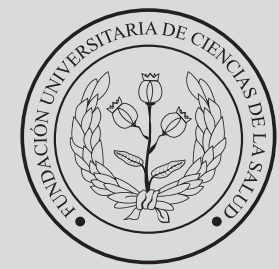

FUCS
Re

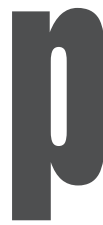

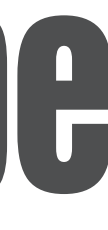

\title{
Encuentro nacional de semilleros. "Un camino hacia la excelencia"
}

\section{Incubator National Meeting: "A path toward excellence"}

${ }^{a} M D ; M S P h D$. Director de Investigaciones. Fundación Universitaria de Ciencias de la Salud. Bogotá DC, Colombia.

Doy inicio a este editorial con la famosa y visionaria descripción del ingeniero eléctrico, mecánico, físico y matemático Nikola Tesla: “Un instrumento de poco costo, y no más grande que un reloj, permitirá a su portador escuchar en cualquier parte, ya sea en el mar o en la tierra, música, canciones o un discurso de un líder político, dictado en cualquier otro sitio distante. Del mismo modo, cualquier dibujo o impresión podrá ser transferida de un lugar a otro". Estas palabras fueron escritas hace más de noventa años por un joven que cultivó el criterio, la persistencia y siempre mantuvo una actitud de servicio a través de la investigación.

Actualmente las universidades son las responsables de formar a los jóvenes investigadores, con el objetivo de incubar la semilla de los futuros generadores del cambio a partir de la investigación; es por ello que dentro de la políticas institucionales de investigación en la Fundación Universitaria de Ciencias de la Salud se promueve el desarrollo de competencias investigativas en los jóvenes estudiantes de pregrado, se incentiva el ejercicio extracurricular de la investigación a través de los semilleros de investigación y la participación de los estudiantes en actividades de divulgación de los resultados de investigación, con la posibilidad de ser coautores de acuerdo con su nivel de contribución. Con el objetivo de fortalecer la socialización y divulgación de resultados de los semilleros de investigación a nivel local y nacional y bajo la organización de la división de investigaciones, la FUCS organizó en julio de 2012 el primer Encuentro Nacional de Semilleros de Investigación en el cual se presentaron 219 trabajos y asistieron 1200 estudiantes provenientes de los semilleros de investigación de 39 facultades de medicina del país.

Ante la acogida del evento por parte de los jóvenes investigadores, la FUCS ha dado continuidad y apoyo a esta iniciativa mediante la realización de dichos encuentros con una periodicidad bienal y el fortalecimiento académico y científico a través de la invitación de conferencistas internacionales de amplio reconocimiento en sus áreas de investigación, quienes durante el evento interactúan con los jóvenes investigadores compartiendo sus experiencias en la generación de nuevo conocimiento.

En el último encuentro de investigación realizado en agosto de 2017, se contó con la participación de más de 800 jóvenes de 59 facultades de medicina y otras áreas de las ciencias de la salud, se presentaron 380 trabajos y asistieron más de 800 jóvenes. El V Encuentro Nacional de semilleros de investigación: “Trabajo colaborativo al servicio de la investigación en salud" contará con la presencia de reconocidos investigadores y académicos como el Dr. Rodolfo Llinas, el exministro de salud y actual rector de la Universidad de los Andes Dr. Alejandro Gaviria y

INFORMACIÓN DEL ARTÍCULO

Historia del artículo: Fecha recibido: mayo 29 de 2019 Fecha aceptado: mayo 30 de 2019
Autor para correspondencia. Dr. Arley Gómez López agomez@fucsalud.edu.co
DOI

10.31260/RepertMedCir.v28.n2.2019.932 
el Dr. Andrés Mauricio Álvarez, médico neurólogo y director de investigación clínica del Sean Parker Center en asma y alergias de la Universidad de Stanford, California. El evento se llevará a cabo en el edificio el Cubo de Colsubsidio los días 21,22 y 23 de agosto. Se espera la participación de más de
800 jóvenes y 450 trabajos de investigación. Sea la oportunidad para reiterar la invitación a todos los docentes y estudiantes de las distintas facultades de ciencias de la salud a participar en este magno evento.

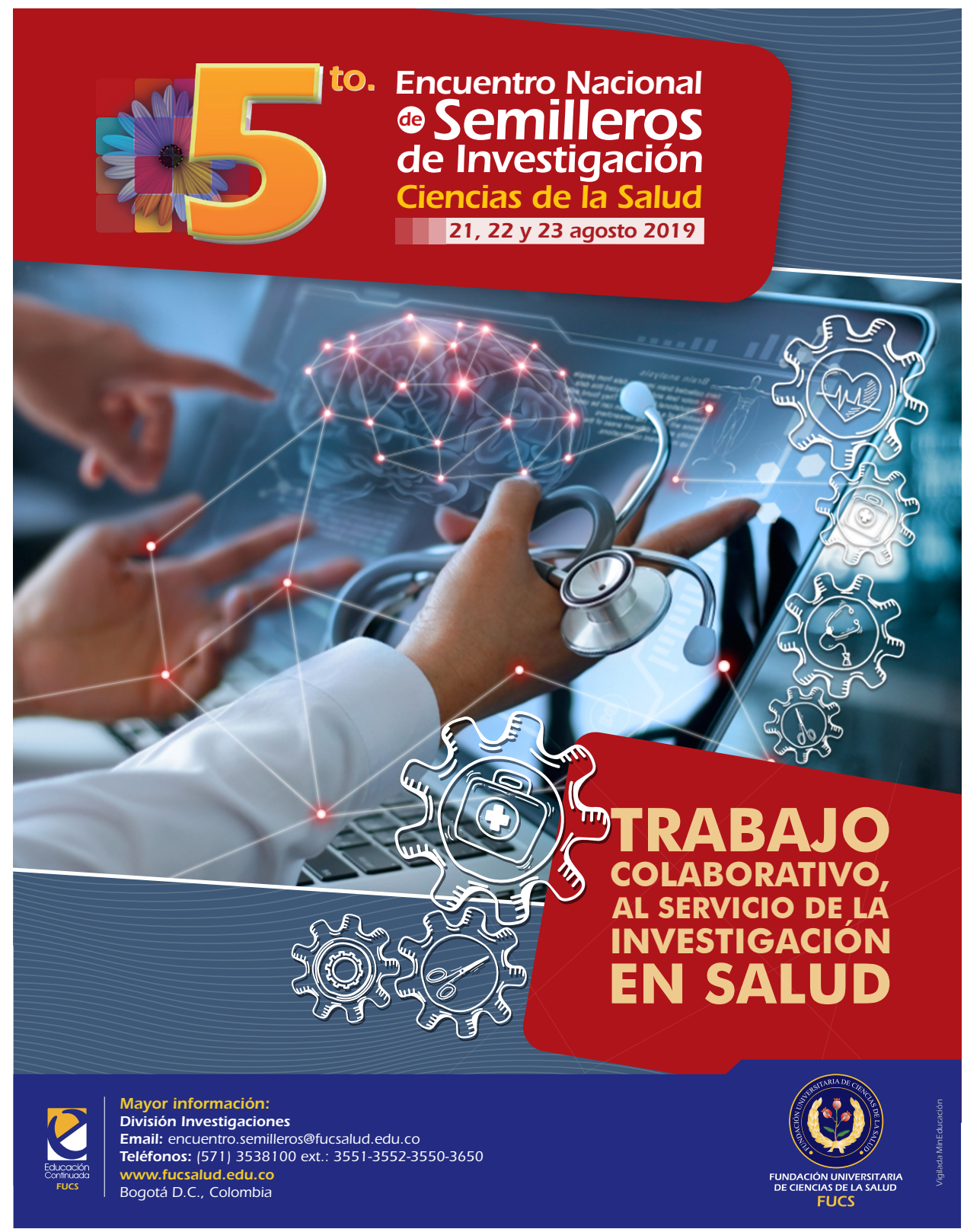

Imágen promocional. 5to Encuentro Nacional de Semilleros de Investigación. 